\title{
Micro-Portion Image Analysis of Light Elements in Fe-Cr Based Alloys by Time-of-Flight Secondary Ion Mass Spectrometry
}

\author{
Rie SHISHIDO, ${ }^{1) *}$ Masahito UCHIKOSHI, ${ }^{1)}$ Shigeo SATO, ${ }^{2)}$ Hidekazu TODOROKI') and Shigeru SUZUKI ${ }^{11}$ \\ 1) Institute of Multidisciplinary Research for Advanced Materials, Tohoku University, Katahira, Aoba-ku, Sendai, Miyagi, 980- \\ 8577 Japan. \\ 2) Graduate School of Science and Engineering, Ibaraki University, Nakanarusawa, Hitachi, Ibaraki, 316-8511 Japan. \\ 3) Technical Research Center, Nippon Yakin Kogyo Co., Ltd, Kojimatyo, Kawasaki-ku, Kawasaki, Kanagawa, $210-8558$ Japan.
}

(Received on February 8, 2017; accepted on April 24, 2017; J-STAGE Advance published date: June 27, 2017)

\begin{abstract}
The mechanical properties of high-alloyed steels are influenced by small amounts of light elements such as hydrogen, carbon, and nitrogen, which are dissolved or precipitated. Thus, it is important to analyze the microscopic distribution of these light elements in the microstructure of steels. Secondary ion mass spectrometry (SIMS) is a powerful method for detecting the distribution of light elements in the microstructure of steels. In this study, time-of-flight secondary ion mass spectrometry (ToF-SIMS) was used to analyze the microscopic distribution of light elements, such as deuterium, carbon, and nitrogen in Fe-Cr based alloys which are typical high-alloys, as ToF-SIMS provides high sensitivity and high spatial resolution. The studied $\mathrm{Fe}-\mathrm{Cr}$ based alloys were a pure ferritic $\mathrm{Fe}-10 \% \mathrm{Cr}$ alloy and a commercial duplex stainless steel consisting of the ferritic and austenitic phases. Both steels were electrochemically charged with deuterium. The results showed that charged deuterium more easily diffuses out of the ferritic $\mathrm{Fe}-10 \% \mathrm{Cr}$ alloy in comparison with the duplex stainless steel, and small amounts of carbon and nitrogen were segregated at grain boundaries in $\mathrm{Fe}-10 \% \mathrm{Cr}$. It was also shown that deuterium, carbon, and nitrogen were heterogeneously distributed in the microstructure of the duplex stainless steel.
\end{abstract}

KEY WORDS: secondary ion mass spectrometry; light elements; deuterium; segregation.

\section{Introduction}

A variety of steel products are utilized as structural materials for e.g. automotive and architectural applications, and chemical plants, and the mechanical properties of these steels are known to be strongly affected by small amounts of light elements, such as hydrogen, carbon, and nitrogen. These elements fundamentally occupy interstitial sites in the crystal structure and are distributed in the microstructure of the steels. It is of great importance to establish methods for analyzing the distribution of these elements in the microstructure of steels, in order to understand influences of these elements on the mechanical properties, which are strongly influenced by the microstructure formed during phase transformations and plastic deformation. The distribution of light elements and alloying elements has not been fully clarified in commercial steel products or iron-based alloys, although many kinds of alloying elements in steel products influence the formation of the microstructure. ${ }^{1)}$

Among the light elements, it is known that the diffusivity of hydrogen in steels is high, while its solubility is very low. ${ }^{2,3)}$ Hydrogen embrittlement often occurs in highstrength steels, including stainless steels, but the mechanism

* Corresponding author: E-mail: rie_s@tagen.tohoku.ac.jp DOI: http://dx.doi.org/10.2355/isijinternational.ISIJINT-2017-046 of hydrogen embrittlement is still unclear. One of the limitations in the study on hydrogen embrittlement is the difficulty of microscopic analysis of hydrogen in steels compared to other light elements, since the solubility of hydrogen in the steels at about room temperature is low. ${ }^{3-7)}$ Thus, it is necessary to establish analysis methods of the microscopic distribution of hydrogen experimentally, although the mechanism of hydrogen embrittlement has been mainly investigated based on atomistic models ${ }^{8-11)}$ and the mechanical properties and the relevant phenomena have been investigated in detail. $^{12-15)}$

On the other hand, analytical methods for investigating the distribution of hydrogen in steels are limited, as the use of vacuum is generally required in such analytical apparatuses. There are several analytical methods that can analyze the distribution of light elements; secondary ion mass spectrometry (SIMS) is useful for detecting the distribution of small amounts of elements in solid materials with complex microstructures. ${ }^{16-18)}$ SIMS has high sensitivity and is hence a powerful tool for detecting hydrogen on solid surfaces; this method is used for the measurement of isotopes such as ${ }^{2} \mathrm{H},{ }^{13} \mathrm{C}$ and ${ }^{18} \mathrm{O}$. Dynamic SIMS with magnetic sector or quadrupole analyzers has been developed for detecting trace elements, or obtaining depth profiles of inorganic materials. However, it is difficult to achieve both high spatial resolution and high depth resolution using this 
method. On the other hand, static SIMS with a time-of-flight (ToF) analyzer can overcome this problem. ToF-SIMS has been used for analyzing various materials, including organics such as polymers and biological tissue. Information about the chemical structure of the topmost atomic layers can be obtained with static SIMS, because the dose density of primary ions is much lower than the surface atomic density. ${ }^{17,18)}$ Moreover, it is also possible to obtain a depth profile using a dual beam technique; the sputtered ions are irradiated to the target after the SIMS measurement with the primary ions, and the bombardment with two ion beams is alternated while the secondary ions emitted from the center of the sputter crater are analyzed. Low energy sputter ion beams are used in this method because the extractor energy of the ToF analyzer is applied intermittently. In recent years, cluster ions such as $\mathrm{Au}_{n}{ }^{+}, \mathrm{Bi}_{n}{ }^{+}, \mathrm{C}_{60}{ }^{+}$, and $\mathrm{Ar}_{n}{ }^{+}$have been adopted as the primary ion source in ToF-SIMS, as such ions enhance the secondary ion yields of macromolecules. ${ }^{19-22)}$ Typically, Bi cluster ToF-SIMS equipped with a liquid metal ion gun (LMIG) has been used for image analysis because the ionized $\mathrm{Bi}_{n}{ }^{q+}$ clusters $(n=1-7, q=$ 1,2 ) achieve high brightness. ${ }^{23,24)}$ Also, it was reported that Bi monomer ions were the optimum primary ion species for analyzing hydrogen and deuterium in materials. ${ }^{25,26)}$

Concerning steels samples, dynamic SIMS has been shown to be an effective method for detecting deuterium or hydrogen in different steels. ${ }^{27-32)}$ These results showed that deuterium or hydrogen is enriched in specific microstructures, although this enrichment depends on the species of steel. The dynamic SIMS has also been applied to observe the distribution of light elements such as boron and nitrogen in steels. ${ }^{33)}$ On the other hand, ToF-SIMS has been used for analyzing the characteristic distribution of deuterium or hydrogen in an $\mathrm{Fe}-\mathrm{Ni}$ alloy and duplex stainless steel. ${ }^{34,35)}$ However, it has been recognized that there are a number of measurement parameters, such as the species of primary ions in ToF-SIMS. By optimizing the analysis conditions, it is expected that this method can be extensively applied to characterize the distribution of light elements in complex microstructures of multi-component materials.

In this study, two $\mathrm{Fe}-\mathrm{Cr}$ based alloys were selected to analyze the distribution of light elements (in particular deuterium, carbon and nitrogen) in the microstructures. One of the $\mathrm{Fe}-\mathrm{Cr}$ based alloys is a highly pure $\mathrm{Fe}-10 \% \mathrm{Cr}$ alloy, which was very carefully prepared from high-purity base metals. ${ }^{36)}$ The investigation of grain boundary segregation of the light elements was a focus of the experiments, since it is known that a small amount of residual nitrogen is segregated to surfaces and grain boundaries. ${ }^{37)}$ Another $\mathrm{Fe}-\mathrm{Cr}$ based alloy studied here is a commercial duplex stainless steel consisting of ferrite and austenite, where the interface between these phases is quite a complicated microstructure. ${ }^{38)}$ The characteristic microstructure of the duplex stainless steel imparts the high toughness and high corrosion resistance, which may be influenced by the distribution of light elements.

\section{Experimental Procedures}

\subsection{Sample Preparation}

The Fe-Cr based alloys analyzed in this study were a pure
Fe-10\%Cr alloy $(10.0 \mathrm{Cr}-0.001 \mathrm{~N}-0.005 \mathrm{C}$; in mass $\%)$ and a duplex stainless steel $(22.4 \mathrm{Cr}-5.3 \mathrm{Ni}-3.2 \mathrm{Mo}-0.35-\mathrm{Si}-1.0 \mathrm{Mn}-$ $0.16 \mathrm{~N}-0.013 \mathrm{C}$; in mass $\%)$. The ferritic $\mathrm{Fe}-10 \% \mathrm{Cr}$ alloy was carefully prepared from high-purity $\mathrm{Fe}$ and $\mathrm{Cr}$ using hydrogen arc plasma processing. ${ }^{36)}$ On the other hand, the duplex stainless steel was the commercially available NAS 329J3L consisting of ferritic and austenitic phases, produced by Nippon Yakin Kogyo Co. Ltd. ${ }^{38)}$ To prepare samples for ToF-SIMS and EPMA, sheets of these Fe-Cr based alloy samples were mechanically and electrochemically polished. The ToF-SIMS and EPMA measurements were conducted for the samples charging with heavy water $\left({ }^{2} \mathrm{H}_{2} \mathrm{O}\right)$.

The present samples were electrochemically charged with deuterium $\left({ }^{2} \mathrm{H}\right)$ in a ${ }^{2} \mathrm{H}_{2} \mathrm{O}$ solution containing $0.1 \mathrm{~N} \mathrm{H}_{2} \mathrm{SO}_{4}$ at a constant current density of $0.1 \times 10^{4} \mathrm{~A} / \mathrm{m}^{2}$ for $24 \mathrm{~h}$. Deuterium in the samples doped with deuterium by cathodic charging was distinguished from hydrogen remaining in vacuum in the SIMS apparatus, which is mainly derived water molecules, ${ }^{39)}$ and detected as a background trace in the SIMS mass spectra. The abundance of the naturally occurring deuterium isotope is approximately ten-thousandth that of hydrogen. The samples were subsequently electrochemically polished to obtain a mirror surface for analysis after charging. Then the quantity and distribution of deuterium in the samples were characterized by ToF-SIMS. After the ToF-SIMS analysis, the samples were subsequently annealed at $673 \mathrm{~K}$ for one hour, in order to investigated the influence of annealing on the distribution of deuterium in the samples. Furthermore, EPMA was used to analyze the distributions of alloying elements in the metallographic microstructure.

\subsection{ToF-SIMS and EPMA Measurements}

ToF-SIMS analysis was carried out in dual-beam depth profile mode with a TOF.SIMS 5 (ION-TOF GmbH, Münster, Germany). A $25 \mathrm{kV}$ pulsed primary $\mathrm{Bi}_{1}{ }^{+}$ion beam bombarded the sample surface at an angle of incidence of $45^{\circ}$. Using monomer ions, it was possible to analyze deuterium with high sensitivity because the quantity of $\mathrm{Bi}_{1}{ }^{+}$was the largest of all primary $\mathrm{Bi}$ ion species. The negatively charged secondary ions were guided to a reflectron-type time-of-flight mass spectrometer (ToF-MS) by an accelerating voltage of $2 \mathrm{kV}$ and reaccelerated to $10 \mathrm{kV}$ before being detected by a micro-channel plate (MCP) detector. The low energy $\mathrm{Cs}^{+}$ions were selected as a source for the sputter ion beam, since a yield of negatively charged secondary ions was effectively generated by $\mathrm{Cs}^{+}$bombardments. The measurements were performed in the interlaced mode to reduce the background resulting from residual gasses, including hydrogen and deuterium. All analyses were conducted under a vacuum pressure of $<2.0 \times 10^{-7} \mathrm{~Pa}$.

The high-current bunched mode $(\mathrm{m} / \Delta m=11000 ; 5$ $\mu \mathrm{m}$ beam diameter) was used to evaluate the quantity of deuterium, where high mass-resolution was achieved to temporarily compress the pulse width of the primary ions; the high current of the primary ions enables high sensitivity detection of secondary ions. The primary ion beams were scanned over a field-of-view of $200 \times 200 \mu \mathrm{m}^{2}$ at a resolution of $128 \times 128$ pixels. The target current of primary ions was $1.25 \mathrm{pA}$ and cycle time defined as the time between two plus was $80 \mu \mathrm{s}$. The accelerating voltage of the sput- 
ter ions was $2 \mathrm{kV}$ and the crater size was $350 \times 350 \mu \mathrm{m}^{2}$. High spatial resolution images were collected in the nonbunched burst alignment mode $(m / \Delta m=500 ; 0.3 \mu$ m beam diameter); a high spatial resolution was desired to avoid the chromatic effect that causes beam divergence. The samples were scanned across a $70 \times 70 \mu \mathrm{m}^{2}$ field-of-view, with a pixel density of $128 \times 128$. The target current was $0.80 \mathrm{pA}$ at $35 \mu$ s cycle time. In this analysis, a $500 \mathrm{~V}$ sputter ion beam irradiated an area of $350 \times 350 \mu \mathrm{m}^{2}$. Because all the secondary ion mass spectra are stored for an analyzed area in the ToF-SIMS analysis, line scans of specific ions can be plotted from the spectral data. Such line scans are useful to investigate the inhomogeneous distribution of elements in a sample.

In order to compare the microscopic distribution of alloying elements with images of secondary ions by ToF-SIMS, elemental maps by EPMA were measured with a JXA-8200 system (JEOL Ltd.). The electron beam was accelerated at $15 \mathrm{kV}$ and the current was $50 \mathrm{nA}$. In this analysis, the characteristic X-rays of nickel, chromium, and molybdenum emitted from the sample were imaged with wavelength dispersive X-ray analyzer (WDX).

\section{Results and Discussion}

\subsection{Detection of Deuterium in Duplex Stainless Steel and Pure Fe-10\%Cr Alloy}

Figure 1 shows images of $\mathrm{H}^{-},{ }^{2} \mathrm{H}^{-}, \mathrm{Fe}^{-}, \mathrm{FeO}^{-}, \mathrm{Cl}^{-}, \mathrm{CH}^{-}$, and $\mathrm{OH}^{-}$ions from the duplex stainless steel charged with ${ }^{2} \mathrm{H}_{2} \mathrm{O}$. These images were obtained by integrating the images measured in depth profiling. In this measurement, the highcurrent bunched mode was used to evaluate the quantity of deuterium. The signals of $\mathrm{Cl}^{-}, \mathrm{CH}^{-}$, and $\mathrm{OH}^{-}$ions are originated from residual gas or surface contaminated particles. The signal intensities of secondary ions arising from surface contamination (the hydrogen-enriched area), were higher than those of all other areas. On the other hand, it is shown that the distribution of secondary ion counts of $\mathrm{Fe}^{-}$ from the total area were almost uniform. In order to avoid the influence of surface contamination, the secondary ion counts from the region of interest (ROI) which was excluding hydrogen-rich area was used for analysis, as shown in Fig. 1(h).

Depth profiles of secondary ions from the ROI were obtained using the secondary ion counts from the blue area shown in Fig. 1(h), in which the mass spectra for each pixel were recorded. The depth profiles of different ions from the ROI in the duplex stainless steel are shown in Figs. 2(a), 2(b), and 2(c). The results show that the signal intensities of $\mathrm{H}^{-}, \mathrm{O}^{-}$, and $\mathrm{OH}^{-}$gradually decreased as the surfaces were sputtered with $\mathrm{Cs}^{+}$ions. This indicates that the secondary ions detected from the outermost surface contained information regarding the residual gas adsorbed onto the sample surfaces. Therefore, the signal intensities over a selected range of data points in the depth profiles away from this surface layer (data point 513-1024) were used for evaluating the quantity of ${ }^{2} \mathrm{H}^{-}$in the sample.

Figures 3(a) and 3(d) show mass spectra concerning $\mathrm{H}^{-}$and ${ }^{2} \mathrm{H}^{-}$ions from the selected data point range in the depth profiles of the duplex stainless steel and the $\mathrm{Fe}-10 \% \mathrm{Cr}$ charged with ${ }^{2} \mathrm{H}_{2} \mathrm{O}$, respectively. Figures 3(b) and 3(c) show mass spectra from the duplex stainless steel, which were kept at room temperature for one month after charging and subsequently annealed at $673 \mathrm{~K}$ after the storage of one month, respectively. All mass spectra were obtained from approximately 150-300 nm depth region. Moreover, these (a)

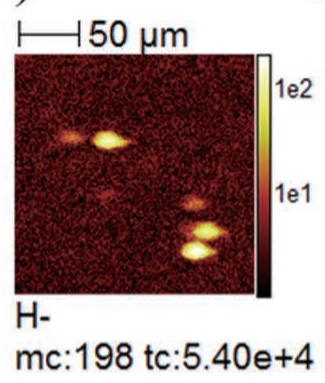

(b)

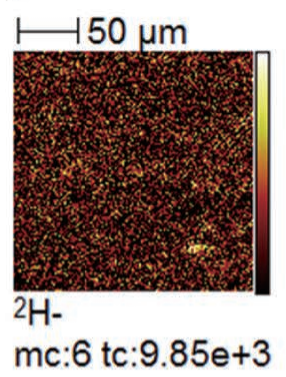

(c)

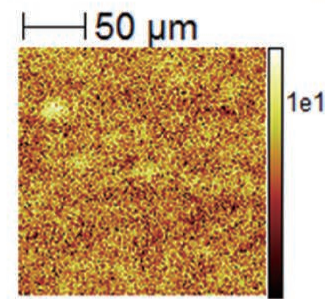

Fe-

$\mathrm{mc}: 18 \mathrm{tc}: 7.12 \mathrm{e}+4$ (d)

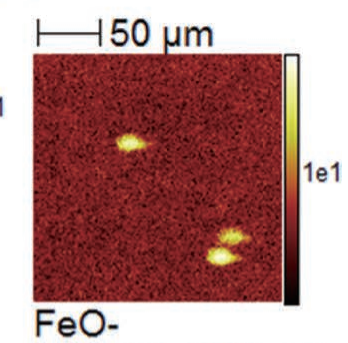

(h)

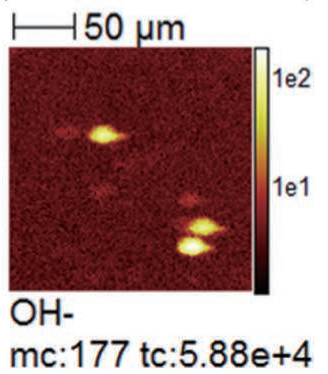

$\mathrm{mc}: 74$ tc: $5.67 e+4$ (g)

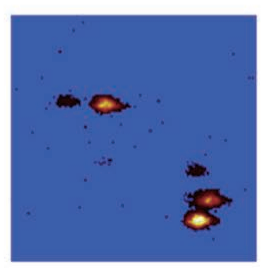

(e)

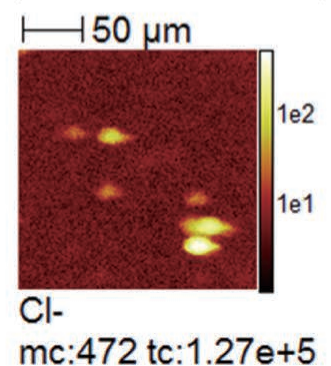

(f)

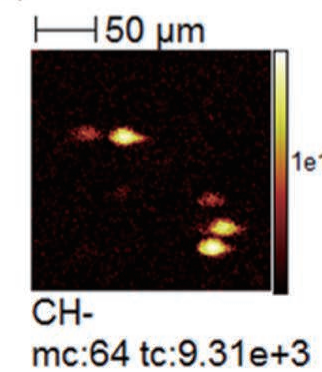

Fig. 1. ToF-SIMS maps of $\mathrm{H}^{-}$(a), ${ }^{2} \mathrm{H}^{-}$(b), $\mathrm{Fe}^{-}$(c), $\mathrm{FeO}^{-}$(d), $\mathrm{Cl}^{-}$(e), $\mathrm{CH}^{-}$(f), and $\mathrm{OH}^{-}$(g) ions from the duplex stainless steel sample charged with ${ }^{2} \mathrm{H}_{2} \mathrm{O}$. These images were obtained from a deep region of depth profiles in high-current bunching mode. (h) shows the blue colored region of interest (ROI), in which the $\mathrm{H}^{-}$-rich area is excluded. Depth profiles were obtained for the ROI. The maximum ion counts are denoted as "mc" in each figure. 
indicated $\mathrm{H}_{2}{ }^{-}$could not be detected in ToF-SIMS depth profile measurements, because it was possible to separate the peaks of ${ }^{2} \mathrm{H}^{-}(\mathrm{m} / \mathrm{z}=2.014)$ and $\mathrm{H}_{2}^{-}(\mathrm{m} / \mathrm{z}=2.016)$ in the measurements of the high-current bunched mode. The signal intensity of $\mathrm{H}^{-}$ions from the annealed duplex stainless steel was similar to that obtained after charging with ${ }^{2} \mathrm{H}_{2} \mathrm{O}$, which is considered as a background level in the present SIMS analysis. This implies that it is very difficult to use $\mathrm{H}^{-}$ions to quantify hydrogen in the samples. On the other hand, the signal intensity of ${ }^{2} \mathrm{H}^{-}$ions indicated that deuterium does not remain in the $\mathrm{Fe}-10 \% \mathrm{Cr}$ after charging. We conclude that the deuterium diffused out of the sample
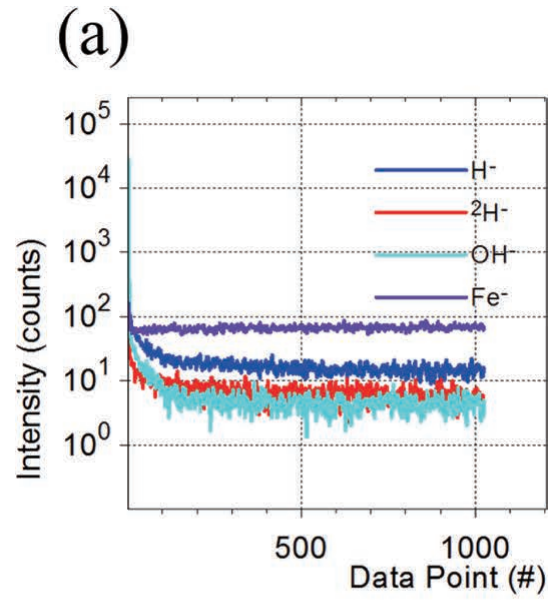

(b)

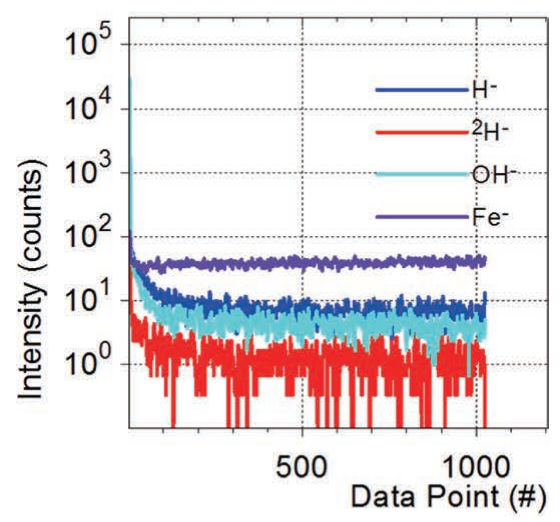

(c)

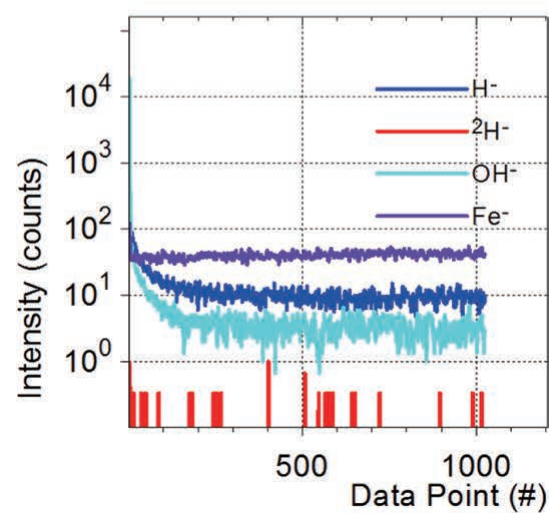

Fig. 2. Depth profiles of the duplex stainless steel (a) charged with ${ }^{2} \mathrm{H}_{2} \mathrm{O}$, (b) subsequently stored in ambient atmosphere for one month, and (c) finally annealed at about $673 \mathrm{~K}$. at room temperature, as the diffusivity of hydrogen is quite high in body-centered-cubic (bcc) Fe-based alloys. ${ }^{4-7)}$ However, it is noted that deuterium was detected in the depth profiles of the duplex stainless steel charged with ${ }^{2} \mathrm{H}_{2} \mathrm{O}$, while it was not detected after annealing. This indicates that deuterium diffuses out of the sample during annealing, and the diffusion of deuterium is slow in the duplex stainless steel at room temperature. In addition, it is interesting to remark that the intensity ratio of ${ }^{2} \mathrm{H}^{-}$to $\mathrm{H}^{-}$obtained for the annealed sample was nearly equal to the abundance ratio of the naturally occurring isotopes. This result suggested that ${ }^{2} \mathrm{H}^{-}$detected in this measurement was derived from residual gas in vacuum chamber, not from charged to the sample. In ToF-SIMS analysis, $\mathrm{H}^{-}$and ${ }^{2} \mathrm{H}^{-}$are detected from all samples as a background. In these case, the intensity counts ratio of $\mathrm{H}^{-}$and ${ }^{2} \mathrm{H}^{-}$calculated from the measured values is equal to isotope ratio. Therefore, it was also indicated that charged deuterium was diffused out from the sample by annealing.

Table 1 summarizes the yields of secondary ions and the values normalized by the $\mathrm{Fe}^{-}$yield of $\mathrm{H}^{-},{ }^{2} \mathrm{H}^{-}, \mathrm{OH}^{-}$, and $\mathrm{Fe}^{-}$ions for the duplex stainless steel and the $\mathrm{Fe}-10 \% \mathrm{Cr}$ alloy. The secondary ion yield is defined the ratio of the secondary ion counts to the total dose of the primary ions. The normalized values of $\mathrm{H}^{-}$and $\mathrm{OH}^{-}$for all samples were nearly similar. The normalized values of ${ }^{2} \mathrm{H}^{-}$obtained from the duplex stainless steel stored for one month after doping with ${ }^{2} \mathrm{H}_{2} \mathrm{O}$ were one hundred times higher than those for the annealed sample. This may be related to the diffusivity and stability of hydrogen in the ferrite and austenite phases. The diffusivity of hydrogen is generally lower in a face-centeredcubic (fcc) than a bcc Fe-based alloy. ${ }^{4)}$ Hence, hydrogen diffuses only a little in the fcc Fe-based alloy at room temperature, and hydrogen seems to be relatively stable in this structure. It is expected that hydrogen may be distributed in the microstructure under such conditions, and therefore it is interesting to observe the images of secondary ions from ToF-SIMS measurements. It is also important to analyze the distribution of light elements, such as carbon and nitrogen in the $\mathrm{Fe}-10 \% \mathrm{Cr}$ alloy by ToF-SIMS, although the amount of hydrogen detected in the $\mathrm{Fe}-10 \% \mathrm{Cr}$ was very small.

\subsection{Imaging of Secondary Ions from Pure Fe-10\%Cr Alloy}

Figure 4 shows the images of negative secondary ions of ${ }^{2} \mathrm{H}^{-}, \mathrm{C}^{-}$, and $\mathrm{CN}^{-}$from the $\mathrm{Fe}-10 \% \mathrm{Cr}$ doped with deuterium. Since the pure $\mathrm{Fe}-10 \% \mathrm{Cr}$ alloy is a polycrystalline ferritic alloy, there are many grain boundaries in the microstructure. The results showed that deuterium was not detected in the pure $\mathrm{Fe}-10 \% \mathrm{Cr}$ alloy, even after intentional charging. This implies that hydrogen diffused out of the sample, as the diffusivity of hydrogen in the ferritic phase is high. It is considered that small amounts of alloying elements in the ferrite act to hold the hydrogen in the microstructure. ${ }^{7)}$ However, such a phenomenon was not observed in the present $\mathrm{Fe}-10 \% \mathrm{Cr}$ alloy, although it has been previously reported that substitutional alloying elements in ferritic iron can reduce hydrogen diffusion. ${ }^{7)}$ Therefore, chromium in the present $\mathrm{Fe}-10 \% \mathrm{Cr}$ alloy does not seem to effectively interact with deuterium. These results are consistent with those from the quantitative evaluation by high-current bunched 


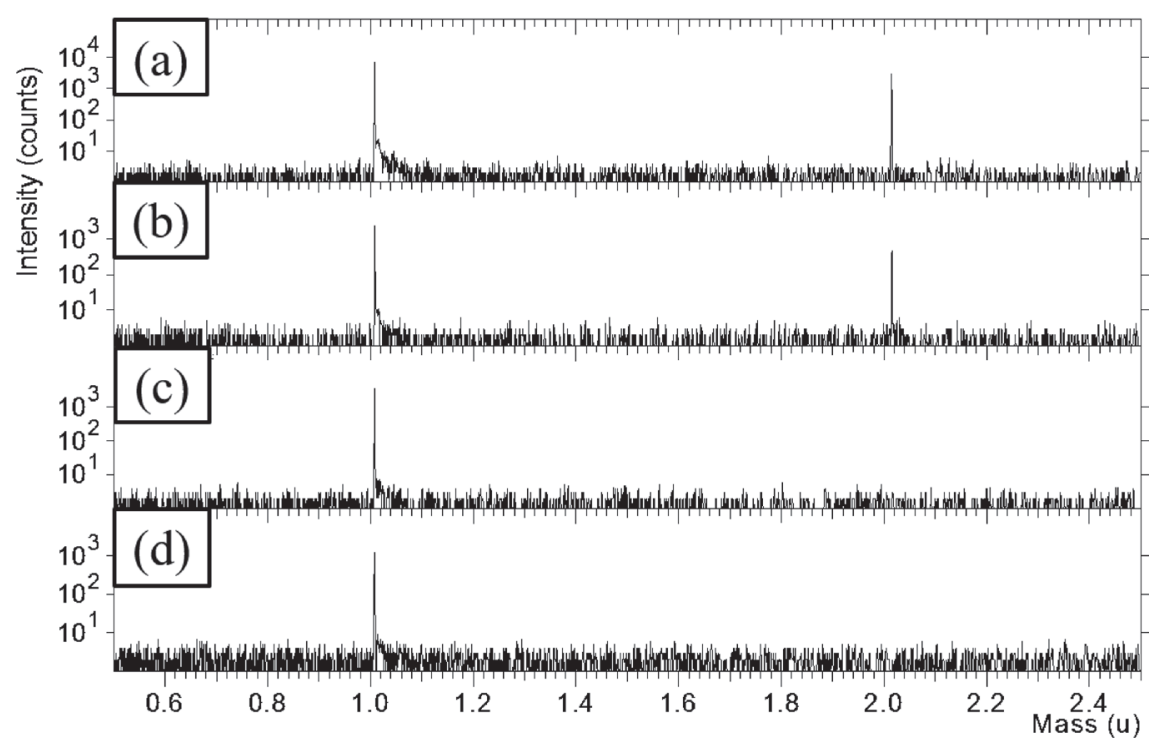

Fig. 3. Mass spectra in the region of hydrogen and deuterium ions from the duplex stainless steel (a) charged with ${ }^{2} \mathrm{H}_{2} \mathrm{O}$, (b) stored for one month after doping, and (c) annealed at $673 \mathrm{~K}$. (d) $\mathrm{Fe}-10 \% \mathrm{Cr}$ alloy charged with ${ }^{2} \mathrm{H}_{2} \mathrm{O}$. These data were obtained from the deep region (data points 513-1024) of the depth profiles shown in Fig. 2.

Table 1. Secondary ion yields and the values normalized by the $\mathrm{Fe}^{-}$yield obtained from mass spectra of the duplex stainless steel (a) charged with ${ }^{2} \mathrm{H}_{2} \mathrm{O}$, (b) subsequently kept for one month after charging, and (c) finally annealed at $673 \mathrm{~K}$. (d) These same values for the Fe$10 \% \mathrm{Cr}$ alloy charged with ${ }^{2} \mathrm{H}_{2} \mathrm{O}$.

(a)

\begin{tabular}{lcccc}
\hline & $\mathrm{H}^{-}$ & ${ }^{2} \mathrm{H}^{-}$ & $\mathrm{OH}^{-}$ & $\mathrm{Fe}^{-}$ \\
\hline Secondary ion yield & $1.5 \times 10^{-6}$ & $6.3 \times 10^{-7}$ & $4.5 \times 10^{-7}$ & $7.0 \times 10^{-6}$ \\
Normalized Fe yield & $2.2 \times 10^{-1}$ & $9.0 \times 10^{-2}$ & $6.4 \times 10^{-2}$ & 1 \\
\hline
\end{tabular}

(b)

\begin{tabular}{lcccc}
\hline & $\mathrm{H}^{-}$ & ${ }^{2} \mathrm{H}^{-}$ & $\mathrm{OH}^{-}$ & $\mathrm{Fe}^{-}$ \\
\hline Secondary ion yield & $6.6 \times 10^{-7}$ & $1.2 \times 10^{-7}$ & $4.2 \times 10^{-7}$ & $3.9 \times 10^{-6}$ \\
Normalized Fe yield & $1.7 \times 10^{-1}$ & $3.1 \times 10^{-2}$ & $1.1 \times 10^{-1}$ & 1 \\
\hline
\end{tabular}

(c)

\begin{tabular}{|c|c|c|c|c|}
\hline & $\mathrm{H}^{-}$ & ${ }^{2} \mathrm{H}^{-}$ & $\mathrm{OH}^{-}$ & $\mathrm{Fe}^{-}$ \\
\hline Secondary ion yield & $9.2 \times 10^{-7}$ & $9.7 \times 10^{-10}$ & $3.2 \times 10^{-7}$ & $4.2 \times 10^{-6}$ \\
\hline Normalized $\mathrm{Fe}^{-}$yield & $2.2 \times 10^{-1}$ & $2.3 \times 10^{-4}$ & $7.8 \times 10^{-2}$ & 1 \\
\hline
\end{tabular}

(d)

\begin{tabular}{|c|c|c|c|c|}
\hline & $\mathrm{H}^{-}$ & ${ }^{2} \mathrm{H}^{-}$ & $\mathrm{OH}^{-}$ & $\mathrm{Fe}^{-}$ \\
\hline Secondary ion yield & $4.1 \times 10^{-7}$ & $4.0 \times 10^{-10}$ & $5.7 \times 10^{-7}$ & $2.8 \times 10^{-6}$ \\
\hline Normalized $\mathrm{Fe}^{-}$yield & $1.5 \times 10^{-1}$ & $1.5 \times 10^{-4}$ & $2.1 \times 10^{-1}$ & 1 \\
\hline
\end{tabular}

mode testing.

Regarding the residual light elements in the $\mathrm{Fe}-10 \% \mathrm{Cr}$ alloy, the intensities of the secondary ions of $\mathrm{C}^{-}$and $\mathrm{CN}^{-}$at grain boundaries should be discussed. Figure 5 shows the line scans of negative secondary ions of $\mathrm{C}^{-}$and $\mathrm{CN}^{-}$from the pure $\mathrm{Fe}-10 \% \mathrm{Cr}$ alloy. These results indicate that carbon and nitrogen were segregated at grain boundaries, although the amounts of these light elements were very small. Although deuterium was not detected in this alloy, this suggests that ToF-SIMS is an effective method for detecting such small amounts of carbon and nitrogen.
From the present results on imaging of secondary ions to detect carbon and nitrogen, it is concluded that microstructural analysis using ToF-SIMS is an effective method for investigating the distribution of light elements; the distribution of deuterium in the duplex stainless steels is shown later.

\subsection{Imaging of Secondary Ions from Duplex Stainless Steel}

The results of the detection of deuterium, as shown in Table 1, suggest that the deuterium distribution in the duplex stainless steel charged with ${ }^{2} \mathrm{H}_{2} \mathrm{O}$ can be visualized using ToF-SIMS, although the signal intensity of deuterium from the $\mathrm{Fe}-10 \% \mathrm{Cr}$ alloy charged with ${ }^{2} \mathrm{H}_{2} \mathrm{O}$ was not high enough to observe the deuterium distribution. Furthermore, mass spectra shown in Fig. 3 indicated that the information of $\mathrm{H}_{2}^{-}$derived from iron hydroxide layer and hydrated iron oxide layer was not included in following images because $\mathrm{H}_{2}{ }^{-}$was not detected in ToF-SIMS depth profile measurements. Thus, high spatial resolution images of ${ }^{2} \mathrm{H}^{-}, \mathrm{C}^{-}$, and $\mathrm{CN}^{-}$ions from the duplex stainless steel using the burst alignment mode are shown in Figs. 6(a) and 6(b), which were charged with ${ }^{2} \mathrm{H}_{2} \mathrm{O}$ and subsequently annealed at 673 $\mathrm{K}$, respectively. These images were obtained from depth profile analysis (approximately 20-60 nm depth region). These results show that the light elements such as deuterium, carbon and nitrogen were heterogeneously distributed in the microstructure, and the deuterium-enriched region is different from that enriched by carbon and nitrogen. In the analysis of the burst alignment mode, high spatial resolution images are able to be obtained because the beam diameter of this mode is $0.3 \mu \mathrm{m}$ which is one-tenth or less than the high-current bunching mode. The latter region is considered to be the austenite phase, as discussed later. The characteristic distribution of deuterium is considered to result from diffusion paths in the ferrite, as the diffusivity in the ferrite is known to be much higher in the ferrite than in the austenite. ${ }^{40)}$ It is noted that deuterium seems to be enriched in the ferrite side close to the interface between the ferrite and the 


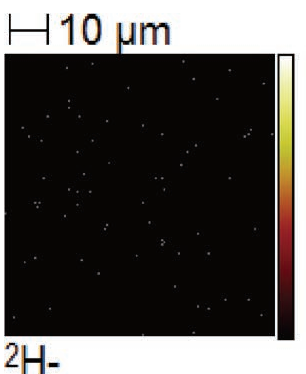

$\mathrm{mc}: 1 \mathrm{tc}: 6.90 \mathrm{e}+1$

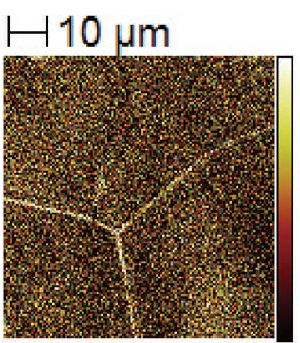

C-

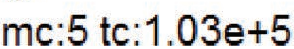

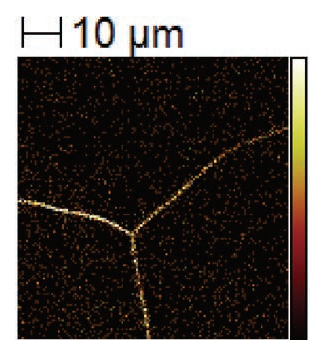

$\mathrm{CN}-$

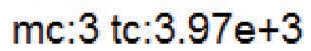

Fig. 4. High spatial resolution images of ${ }^{2} \mathrm{H}^{-}, \mathrm{C}^{-}$, and $\mathrm{CN}^{-}$from the $\mathrm{Fe}-10 \% \mathrm{Cr}$ alloy obtained using the burst alignment mode. Although these were measured by depth profiling after charging with ${ }^{2} \mathrm{H}_{2} \mathrm{O}$, significant deuterium was not detected. (Online version in color.)

(a)

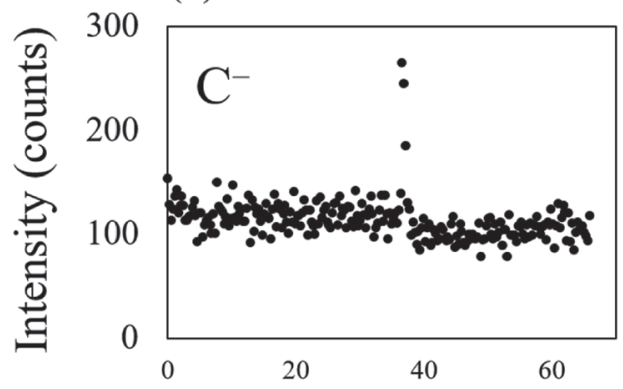

(b)

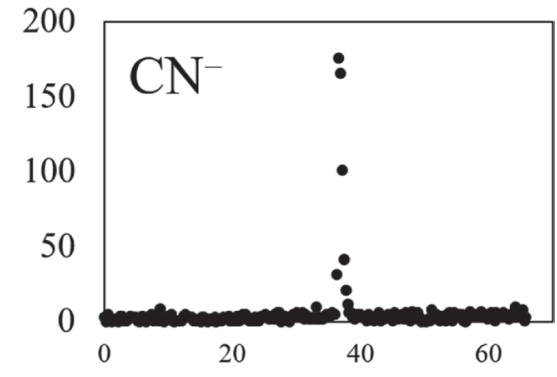

Distance $(\mu \mathrm{m})$

Fig. 5. Line scans of (a) $\mathrm{C}^{-}$and (b) $\mathrm{CN}^{-}$ions from a region crossing a grain boundary in the $\mathrm{Fe}-10 \% \mathrm{Cr}$ alloy charged with ${ }^{2} \mathrm{H}_{2} \mathrm{O}$.

(a)

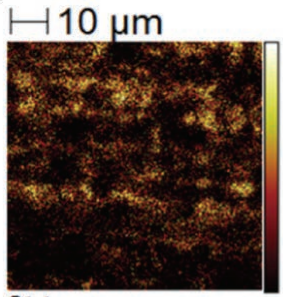

$2 \mathrm{H}-$

$\mathrm{mc}: 8$ tc: $6.73 \mathrm{e}+4$

(b)

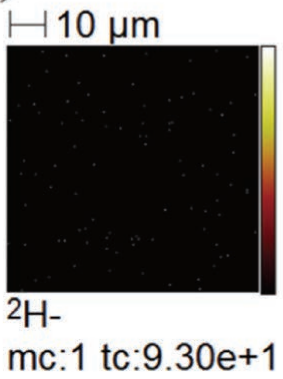

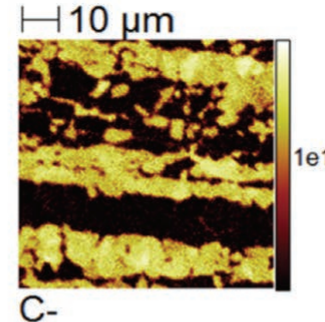

mc:40 tc: $5.30 \mathrm{e}+5$

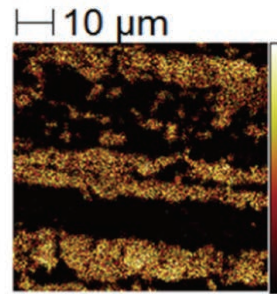

$\mathrm{CN}-$

mc:8 tc: $7.90 \mathrm{e}+4$ austenite. Since the practical morphology of the interface is complicated, deuterium may be trapped in such complicated microstructure.

In order to investigate the correlation between the distri-

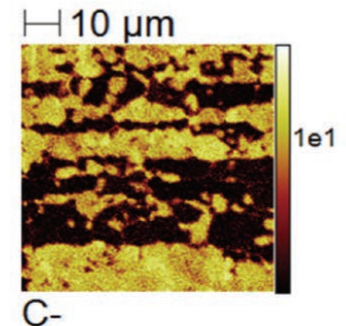

C-

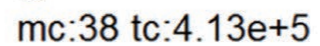

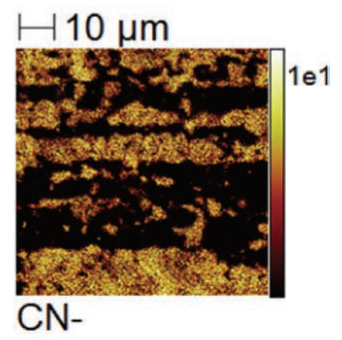

$\mathrm{mc}: 13$ tc: $1.31 \mathrm{e}+5$

Fig. 6. High spatial resolution ToF-SIMS images for ${ }^{2} \mathrm{H}^{-}, \mathrm{C}^{-}$, and $\mathrm{CN}^{-}$from the duplex stainless steel sample (a) charged with ${ }^{2} \mathrm{H}_{2} \mathrm{O}$ and (b) subsequently annealed at $673 \mathrm{~K}$. These images were obtained from the deep region by depth profiles using the burst alignment mode. (Online version in color.)

bution of different elements, line scans of $\mathrm{H}^{-},{ }^{2} \mathrm{H}^{-}, \mathrm{C}^{-}, \mathrm{CN}^{-}$, $\mathrm{CrN}^{-}, \mathrm{FeN}^{-}$, and $\mathrm{Ni}^{-}$ions obtained from the images of the duplex stainless steel charged with ${ }^{2} \mathrm{H}_{2} \mathrm{O}$ are shown in Fig. 7. As the nickel-enriched region is the austenite phase, the 
(a)

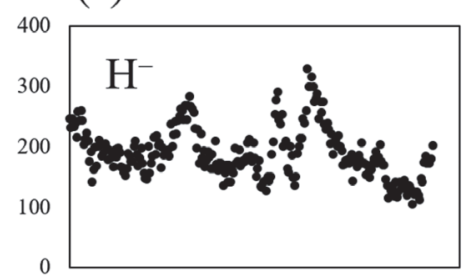

(c)

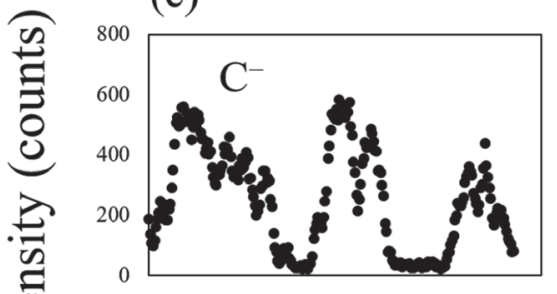

(e)

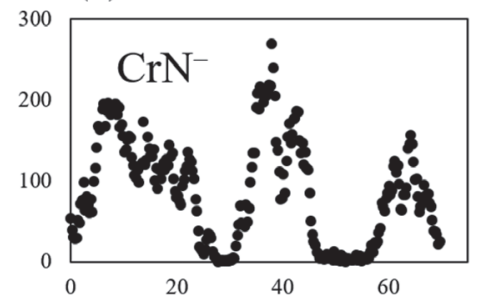

(b)

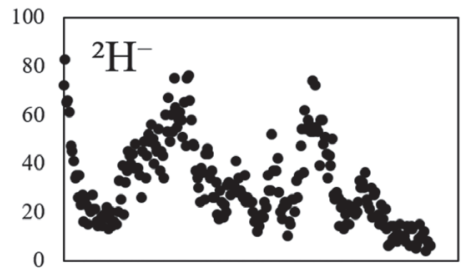

(d)

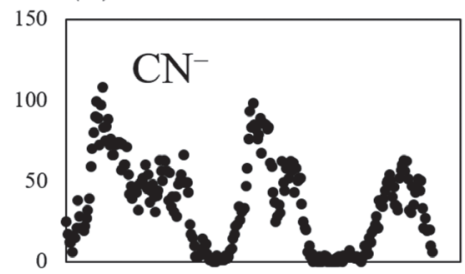

(f)

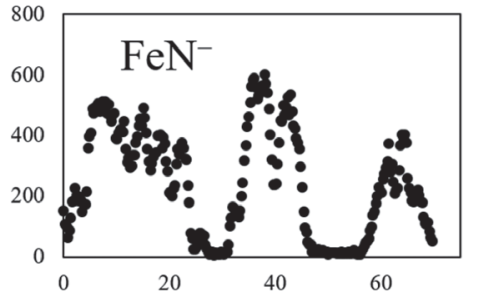

(g)

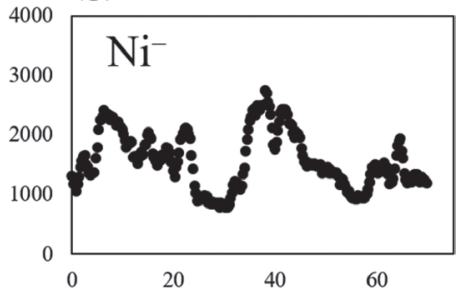

Distance $(\mu \mathrm{m})$

Fig. 7. Line scans of $\mathrm{H}^{-}$(a), ${ }^{2} \mathrm{H}^{-}$(b), $\mathrm{C}^{-}$(c), $\mathrm{CN}^{-}$(d), $\mathrm{CrN}^{-}$(e), $\mathrm{FeN}^{-}$(f), and $\mathrm{Ni}^{-}$(g) from the ToF-SIMS images of the duplex stainless steel charged with ${ }^{2} \mathrm{H}_{2} \mathrm{O}$.

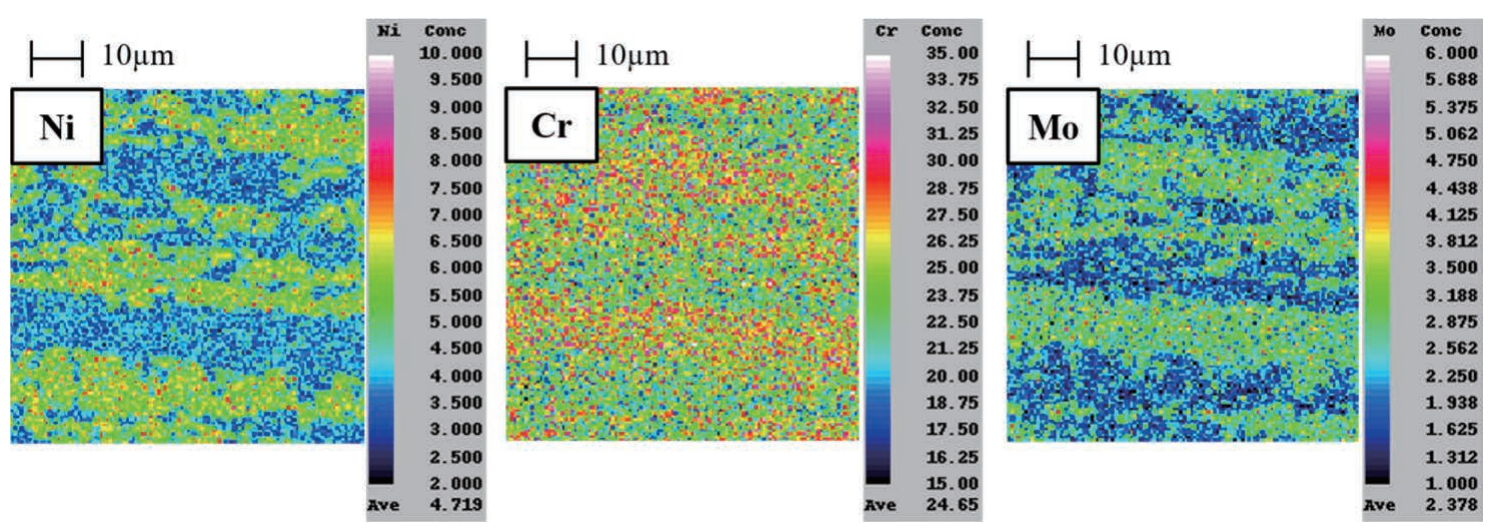

Fig. 9. Elemental maps of nickel, chromium, and molybdenum in the duplex stainless steel obtained by EPMA measurements. These images were measured over the same area as analyzed by ToF-SIMS.

line scan data shown in Fig. 7 indicate that the ${ }^{2} \mathrm{H}^{-}$signal, arising from deuterium in the sample, is generally higher in the ferrite than in the austenite (in which the signal intensities of $\mathrm{C}^{-}$and $\mathrm{XN}^{-}(\mathrm{X}=\mathrm{C}, \mathrm{Cr}, \mathrm{Fe})$ are high). However, the concentration of deuterium appears to be relatively high in the fine microstructure close to the interface between the ferrite and austenite phases. Furthermore, although the line scan data of ${ }^{2} \mathrm{H}^{-}$ions are not shown here, it was found that the counts of ${ }^{2} \mathrm{H}^{-}$ions were very low in the duplex stainless steel annealed at $673 \mathrm{~K}$. This corresponds well to the results shown in Fig. 6(b).

In order to compare the distribution of deuterium and carbon, images of secondary ions from the duplex stainless steel charged with ${ }^{2} \mathrm{H}_{2} \mathrm{O}$ were normalized, as shown in Fig. 8. The red area indicates the ${ }^{2} \mathrm{H}^{-}$ion count normalized by

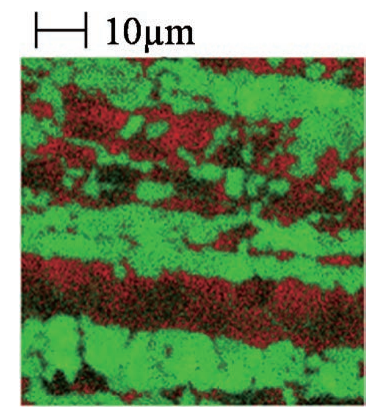

Fig. 8. Normalized image of the duplex stainless steel charged with ${ }^{2} \mathrm{H}_{2} \mathrm{O}$. The red area indicates ${ }^{2} \mathrm{H}^{-}$ion counts normalized by $\mathrm{C}^{-}$ion counts, whereas the green area shows $\mathrm{C}^{-}$ ion counts normalized by ${ }^{2} \mathrm{H}^{-}$ion counts. 
the $\mathrm{C}^{-}$ion count, whereas the green area shows the $\mathrm{C}^{-}$ion count normalized by the ${ }^{2} \mathrm{H}^{-}$ion count. The superimposed images of deuterium and carbon indicate that these elements were heterogeneously distributed in the microstructure. For comparison, the elemental images of nickel, chromium, and molybdenum in the same area analyzed by EPMA are shown in Figs. 9(a), 9(b) and 9(c), respectively. These results show that the high chromium and molybdenum area corresponds to the ferrite phase, while the high nickel area is the austenite. From the comparison of the superimposed images of deuterium and carbon with the maps of these alloying elements, we can conclude that carbon is enriched in the austenite, whereas deuterium is heterogeneously enriched near the edges of the ferrite-austenite interface. Such behavior has been observed in previous studies for duplex stainless steels, although the composition and microstructure were not identical to the sample investigated here. ${ }^{34,35)}$ A major difference between the present study and the previous work is observed in the microstructure of the samples, especially the rough morphology near the ferriteaustenite interfaces. ${ }^{34,35)}$ The characteristic morphology of the microstructure may influence the stability and diffusivity of deuterium in the duplex stainless steel, although further studies are required to confirm this. In conclusion, the microscopic analysis of light elements using ToF-SIMS is thought to be a promising tool for analyzing the distribution of light elements. Analyzed results provide information for controlling the microstructure of duplex stainless steels, since the mechanical properties of the duplex stainless steels are known to be strongly dependent on the microstructure. ${ }^{38)}$

\section{Summary}

ToF-SIMS was carefully used for analyzing light elements, such as hydrogen, deuterium, carbon, and nitrogen, in a ferritic $\mathrm{Fe}-10 \% \mathrm{Cr}$ alloy and a commercial duplex stainless steel consisting of austenitic and ferritic phases. EPMA was also applied to analyze the distribution of the alloying elements. The main results of this study are as follows:

(1) The present results obtained by ToF-SIMS indicated that it is difficult to directly analyze hydrogen in the $\mathrm{Fe}-\mathrm{Cr}$ based alloys. Signals from hydrogen gas remaining in the vacuum are considered to interfere with the analysis of hydrogen when using ToF-SIMS.

(2) Imaging of secondary ions by ToF-SIMS showed that a small amount of residual carbon and nitrogen were segregated at the grain boundaries in the $\mathrm{Fe}-10 \% \mathrm{Cr}$ alloy. Although the $\mathrm{Fe}-10 \% \mathrm{Cr}$ alloy was charged with deuterium, it was not clearly detected by the SIMS analysis. This may be due to the fast diffusion of hydrogen or deuterium in the bcc ferritic phase.

(3) In the duplex stainless steel, deuterium was detected in the matrix by ToF-SIMS analysis. Deuterium tended to be distributed in the ferritic phase rather than in the austenitic phase. This may have arisen from the higher diffusivity of deuterium in the ferrite than in the austenite.

(4) The analytical results of the duplex stainless steel by ToF-SIMS and EPMA suggested that alloying elements or crystalline defects in the ferritic phase near the interface between the ferrite and austenite seems to play an impor- tant role in the heterogeneous distribution of deuterium in the microstructure, although further systematic studies are required.

\section{Acknowledgements}

This work was supported by a Promotion Grant from the Iron and Steel Institute of Japan and the Research Program of the "Dynamic Alliance for Open Innovation Bridging Human, Environment and Materials" in the "Network Joint Research Center for Materials and Devices".

\section{REFERENCES}

1) W. C. Leslie: The Physical Metallurgy of Steels, McGraw-Hill, New York, (1981), 110.

2) A. R. Troiano: Trans. ASM, 52 (1960), 54

3) R. A. Oriani: Ber. Bunsenges. Phys. Chem., 76 (1972), 848.

4) J. Völkl and G. Alefeld: Diffusion in Solids, ed. by A. S. Nowick and J. J Burton, Academic Press, New York, (1975), 231

5) H. Hagi and Y. Hayashi: Trans. Jpn. Inst. Met., 28 (1987), 368.

6) H. Hagi: Trans. Jpn. Inst. Met., 28 (1987) 375.

7) H. Hagi: Mater. Trans. JIM, 33 (1992), 472.

8) J. Song and W. A. Curtin: Acta Mater., 59 (2011), 1557.

9) J. Song and W. A. Curtin: Nat. Mater., 12 (2013), 145.

10) S. Taketomi, R. Matsumoto and N. Miyazaki: Int. J. Mech. Sci., 52 (2010), 334.

11) M. Wen, S. Fukuyama and K. Yokogawa: Acta Mater., 51 (2003), 1767.

12) D. P. Abraham and C. J. Altstetter: Metall. Mater. Trans. A, A26 (1995), 2859.

13) D. P. Abraham and C. J. Altstetter: Metall. Mater. Trans. A, A26 (1995), 2849.

14) T. Doshida, H. Suzuki, K. Takai, N. Oshima and T. Hirade: ISIJ Int., 52 (2012), 198.

15) T. Doshida, M. Nakamura, H. Saito, T. Sawada and K. Takai: Acta Mater., 61 (2013), 7755.

16) S. Hofmann: Auger and X-ray Photoelectron Spectroscopy in Materials Science, Springer, Berlin Heidelberg, (2012), 77.

17) A. Benninghoven: Phys. Status Solidi, 34 (1969), K169.

18) A. Brown and J. C. Vickerman: Surf. Interface Anal., 6 (1984), 1.

19) N. Davies, D. E. Weibel, P. Blenkinsopp, N. Lockyer, R. Hill and J. C. Vickerman: Appl. Surf. Sci., 203 (2003), 223.

20) F. Kollmer: Appl. Surf. Sci., 231 (2004), 153

21) N. Winograd: Anal. Chem., 77 (2005), 142A.

22) S. Ninomiya, K. Ikichi, H. Yamada, Y. Nakata, T. Seki, T. Aoki and J. Matsuo: Nucl. Instrum. Methods Phys. Res. B, 256 (2007), 493.

$23)$ D. Touboul, F. Kollmer, E. Niehuis, A. Brunelle and O. Laprévote: J. Am. Soc. Mass Spectrom., 16 (2005), 1608.

24) H. Nygren, B. Hagenhoff, P. Malmberg, M. Nilsson and K. Richter: Microsc. Res. Tech., 70 (2007), 969.

25) Z. Zhu and V. Shutthanandan: Surf. Interface Anal., 44 (2012), 89.

26) Z. Zhu, V. Shutthanandan and M. Engelhard: Surf. Interface Anal., 44 (2012), 232.

27) K. Takai, J. Seki and Y. Homma: Mater. Trans. JIM, 36 (1995), 1134.

28) R. Ohtra, C. Bouillot and T. Magnin: Scripta. Mater., 35 (1996), 1101.

29) K. Takai, Y. Chiba, K. Noguchi and A. Nozue: Metall. Mater. Trans. A, 33A (2002), 2659.

30) T. Awane, Y. Fukushima, T. Matsuo, S. Matsuoka, Y. Murakami and S. Miwa: Anal. Chem. 83 (2011), 2667.

31) A. Nishimoto, M. Koyama, S. Yamato, Y. Oda, T. Awane and H. Noguchi: ISIJ Int., 55 (2015), 335.

32) J. Yamabe, T. Awane and S. Matsuoka: Int. J. Hydrog. Energy, 40 (2015), 1175.

33) S. Hashimoto, S. Doi, M. Terasaka and M. Iwaki: Mater. Sci. Eng., 90 (1987), 119.

34) T. Tanaka, K. Kawakami and S.-I. Hayashi: J. Mater. Sci., 49 (2014), 3928.

35) O. Sobol, F. Straub, Th. Wirth, G. Holzlechner, Th. Boellinghaus and W. E. S Unger: Sci. Rep., 6 (2016), 19929.

36) M. Isshiki, K. Mimura and M. Uchikoshi: Thin Solid Films, 519 (2011), 8451.

37) S. Suzuki: Mater. Trans. JIM, 12 (1990), 1085

38) N. Kato, S. Sato, Y. Saito, H. Todoroki and S. Suzuki: Adv. X-ray Chem. Anal. Jpn., 47 (2016), 167 (in Japanese).

39) C. W. Magee and E. M. Botnick: J. Vac. Sci. Technol., 19 (1981), 47.

40) Y. Murakami, T. Kanezaki and Y. Mine: Metall. Mater. Trans. A, 141 (2010), 2548. 